\title{
Effects and Mechanism of Ganoderma lucidum Polysaccharides in the Treatment of Diabetic Nephropathy in Streptozotocin-Induced Diabetic Rats
}

\author{
Yu Hu, ${ }^{1,2}$ Shu-Xiang Wang $\mathbb{D}^{1}{ }^{1}$ Fu-Yu Wu, ${ }^{2}$ Ke-Jia Wu, ${ }^{2}$ Rui-Ping Shi, ${ }^{2}$ Li-Hong Qin, ${ }^{2}$ \\ Chun-Feng Lu, ${ }^{3}$ Shu-Qiu Wang, ${ }^{1}$ Fang-Fang Wang, ${ }^{1}$ and Shaobo Zhou ${ }^{4}$ \\ ${ }^{1}$ Basic Medical College, Jiamusi University, Jiamusi, Heilongjiang, China 154002 \\ ${ }^{2}$ School of Medicine, The First Affiliated Hospital of Jiamusi University, Jiamusi 154003, China \\ ${ }^{3}$ School of Medicine, Huzhou University, Huzhou Central Hospital, Huzhou 313000, China \\ ${ }^{4}$ School of Life Sciences, Institute of Biomedical and Environmental Science and Technology, University of Bedfordshire, Luton, UK \\ LU1 3JU
}

Correspondence should be addressed to Shu-Xiang Wang; shuxiang_wsx@163.com and Shaobo Zhou; shaobo.zhou@beds.ac.uk Received 5 November 2021; Accepted 7 January 2022; Published 8 March 2022

Academic Editor: Abdul Rehman Phull

Copyright (C) $2022 \mathrm{Yu} \mathrm{Hu}$ et al. This is an open access article distributed under the Creative Commons Attribution License, which permits unrestricted use, distribution, and reproduction in any medium, provided the original work is properly cited.

Ganoderma lucidum polysaccharides (GLP) have renal protection effect but there was no study on the diabetic nephropathy. This study was designed to investigate its effect and mechanism using a diabetic rat model induced by streptozotocin (50 mg/kg, i.p.). The diabetic rats were treated with GLP (300 mg/kg/day) for 10 weeks. The blood glucose, glycated hemoglobin, body weight, and the levels of blood creatinine, urea nitrogen, and urine protein were assessed. And renal pathologies were assessed by the tissue sections stained with hematoxylin-eosin, Masson's trichome, and periodic acid-Schiff. The expression of phosphorylated phosphoinositide 3 kinase (p-PI3K), phosphorylated protein kinase B (p-Akt), and phosphorylated mammalian target of rapamycin (p-mTOR), the autophagy proteins beclin-1, LC3-II, LC3-I, and P62; the apoptosis-related proteins caspase-3 and caspase-9; and the inflammation markers IL-6, IL-1 $\beta$, and TNF-a were assessed. Results showed that GLP alleviated the impairment of renal function by reducing urinary protein excretion and the blood creatinine level and ameliorated diabetic nephropathy. The expression of p-PI3K, p-Akt, and p-mTOR in the diabetic kidney were significantly reduced in the GLP treatment group compared to the without treatment group. GLP treatment activated the autophagy indicators of beclin-1 and the ratio of LC3-II/LC3-I but reduced p62 and also inhibited the expression of caspase-3, caspase- 9 and IL-6, IL- $1 \beta$, and TNFa. In conclusion, the effect of GLP amelioration diabetic nephropathy may be via the PI3k/Akt/mTOR signaling pathway by inhibition of the apoptosis and inflammation and activation of the autophagy process.

\section{Introduction}

Diabetic nephropathy, a most common complication of glomerulosclerosis, is one of the important factors leading to renal failure in diabetic patients [1]. With the increase in newly diagnosed cases and a 5-year survival rate of approximately $20 \%$, diabetic nephropathy has caused widespread concern [2]. Genetic, oxidative stress, hemodynamic abnormalities, and inflammatory responses are all related to the onset of diabetic nephropathy [3-5]. Presently, clinical treatment mainly aims to alleviate kidney injury by controlling blood sugar, blood lipid, and blood pressure; however, this action can only slow down the process of renal failure and cannot prevent or reverse the development of the disease. Therefore, finding an efficacious medication for diabetes and its complications, e.g., diabetic nephropathy, is critical in clinical practice.

Ganoderma lucidum, an oriental porous fungus, contains a variety of active substances. Ganoderma lucidum polysaccharides (GLP), one of its active ingredients, have unique medicinal and healthcare value and have attracted various research interests [6]. GLP have important biological 
activities, such as immunoregulation, anti-inflammatory, and antiaging effects, lowering blood glucose, and protecting the liver [6-9], but there is no research on its antinephropathic effect. Zhu et al. [9] isolated and purified a new polysaccharide (PSG-1) from Ganoderma lucidum and found that it significantly reduced fasting blood glucose levels, improved endothelium-dependent aorta relaxation, and increased phosphatidylinositol 3-kinase (PI3K), phosphorylated AKT (pAkt), endothelial nitric oxide synthase (eNOS), and nitric oxide in the aorta of diabetic rats. After binding insulin to its receptor, PSG-1 can also activate the insulin receptor tyrosine kinase and phosphorylate it to produce PI3K [10]. One regulator of mesangial dysfunction in hyperglycaemia is mammalian target of rapamycin (mTOR) which plays a role in the occurrence and development of diabetic nephropathy. Its downstream effectors play a key role in cell growth and hypertrophy, while the inhibition of mTOR by rapamycin can prevent the development of diabetic nephropathy in animals with type 1 and type 2 diabetes [11].

Autophagy is a self-protection mechanism in cells. It can obtain energy by removing and degrading damaged organelles and recycling the biological macromolecules in the cell to maintain the metabolic balance and the stability of the internal environment [12]. Many studies have shown that autophagy is involved in the pathogenesis of diabetic nephropathy, and that it could serve as a new therapeutic target in the treatment of this condition [13]. Autophagy is an intracellular catabolic process, in which lysosomes are involved in the aging and degradation of damaged organelles and proteins, while LC3 and beclin-1 proteins are early marker proteins of autophagy. Apoptosis, also known as programmed cell death, is an important form of cell homeostasis.

Immune system activation and inflammatory response play important roles in the occurrence and development of diabetic nephropathy. Immune cells such as macrophages are involved in prediabetic nephropathy and renal function damage, and monocyte macrophages can also produce cytokines such as IL-6, IL- $1 \beta$, and TNF- $\alpha$. Together with other inflammatory factors, they are involved in the development of diabetic microvascular disease. TNF- $\alpha$ is an important proinflammatory cytokine and is part of the acute phase response. It is mainly produced by macrophages and monocytes; however, increased expression of TNF- $\alpha$ has been observed in glomeruli and proximal tubular epithelial cells in a diabetic nephropathy model [14]. Through NF- $\kappa \mathrm{B}$ signaling, TNF- $\alpha$ can induce the transcription of cytokines, thereby, affecting the survival, proliferation, and adhesion of cells and promoting inflammatory responses and apoptosis. The occurrence of apoptosis is regulated by cysteinespecific protease (caspases). Caspase- 9 is an important initiating factor in the process of apoptosis, while caspase- 3 is the executive factor in the process of apoptosis.

This study intends to further explore the effect of GLP in protecting the kidney of diabetic rats with respect to its effect on the PI3K/Akt/mTOR signaling pathway as well as on autophagy, apoptosis, and inflammation, in order to further evaluate the application of GLP as a new agent in the prevention and treatment of diabetic nephropathy.

\section{Materials and Methods}

2.1. Animals and Research Protocols. This study was approved by the Research Ethics Committee of Jiamusi University (No. 216-JMSU). All steps were taken to reduce animal suffering by following the guideline of using laboratory animals by the Chinese Ministry of Science and Technology. Thirty 8-week-old male specific-pathogen-free (SPF) SD rats, weighing 180-220 g, animal license number: SCXK (Lu) 20140007, were purchased from the Animal Experiment Centre of Jiamusi University. All rats were kept in a laminar flow rack of the SPF Laboratory Animal Center of Jiamusi University. They were placed in an environment with sufficient air circulation and a humidity of $40-70 \%$ at a temperature of $22-25^{\circ} \mathrm{C}$. They were exposed to $12 \mathrm{~h}$ of light, fed with ordinary chow, and provided free access to diet and drinking water for a week. Eight rats were used as a blank control, and the other remaining rats were injected with citric acid-sodium citrate buffer solution in the tail vein. After $12 \mathrm{~h}$ of fasting, each rat received a single intraperitoneal injection of streptozotocin $50 \mathrm{mg} / \mathrm{kg}$ (Sigma company, USA), and they were provided free access to food after injection. Three days later, fasting blood glucose levels were measured using a blood glucose test strip and a Sinocare ultrasimple blood glucose meter (GA-3); 16 rats with blood glucose values greater than $16.7 \mathrm{mmol} / \mathrm{L}$ were randomly divided into a diabetic group and diabetic+GLP group, with 8 animals in each group. The animals were provided normal chow.

The diabetic group was administered saline, the diabetic +GLP group was orally administered GLP (300 mg/kg body weight, per day), and the dosage was based on the previous studies used to efficient lower blood glucose $[15,16]$ as well as the hypolipidaemic effect [17] which also linked to the diabetic nephropathy. Body weight and fasting blood glucose levels were monitored weekly. After 10 weeks, the rats were placed in a metabolic cage individually to collect urine for $24 \mathrm{~h}$. Subsequently, the rats were euthanized with isofluorane (3\% for induction, $2 \%$ for maintenance), blood was collected from the eyeballs and centrifuged at $3000 \times \mathrm{g}$ for $15 \mathrm{~min}$ at $20^{\circ} \mathrm{C}$, the serum was separated from the cells, and the samples were stored at $-80^{\circ} \mathrm{C}$ for further analysis. The left kidney was removed and placed in fixation solution for histological and immunohistochemical staining, and the right kidney was stored at $-80^{\circ} \mathrm{C}$ for analysis including western blot detection.

2.2. Urine Protein, Serum Creatinine, and Blood Urea Nitrogen Measurement. Renal function was evaluated by measuring renal function indicators, including $24 \mathrm{~h}$ urine protein, serum creatinine, and blood urea nitrogen. All kits (Cat. C035-2, C011-2 and C013-2, respectively) were bought from Nanjing Jiancheng Bioengineering Institute (Nanjing, China), and the measurements were performed according to their instructions. The urine protein measurement is based on Microprotein Coomassie Brilliant Blue method. A urinary protein is introduced as a calibrator to improve the determination. Serum creatinine was measured based on colorimetric assay. Creatinine can be catalyzed by 
sarcosamine hydrolases and generates creatine which can be hydrolyzed into sarcosine and urea by creatine amine hydrolase. The sarcosine is broken down by sarcosine oxidase to generate glycine, formaldehyde, and hydrogen peroxide. The reaction between hydrogen peroxide, 2,4-(6-tri-iodine3 - hydroxybenzoic acid) and 4-ampyrone can be catalyzed by peroxidase and form pink compound. Its optical density value at $515 \mathrm{~nm}$ can be used to calculate creatinine content. Blood urea nitrogen was measured by diacetyloxime colorimetry, and urea can react with diacetyl to form red diazine compound. The depth of color is proportional to the content of urea.

2.3. Hematoxylin-Eosin (HぬE) Staining. Partial tissue of rat kidney was collected, fixed with $4 \%$ formaldehyde solution, and gradually dehydrated with a gradient of $75 \%, 80 \%$, $95 \%$, and $100 \%$ ethanol. Next, the tissue was embedded in paraffin, and sections with $3 \mu \mathrm{m}$ thickness were cut using a microtome. After the xylene dewaxing treatment, the sections were washed with absolute ethanol, followed by washing with distilled water for $2 \mathrm{~min}$. Next, the sections were stained with hematoxylin for $5 \mathrm{~min}$, washed with tap water for $1 \mathrm{~min}$, subjected to hydrochloric acid-ethanol differentiation for $15 \mathrm{sec}$, soaked in warm water at $50^{\circ} \mathrm{C}$ for $3 \mathrm{~min}$, stained with eosin for $1 \mathrm{~min}$, and dehydrated with gradient ethanol and xylene medium. They were sealed with dry gum when they were dried and, subsequently, observed under a $\times 400$ microscope (M165FC; Leica) to observe the pathological structure of rat kidneys. The cytoplasm was stained pink, and the nuclei were stained blue.

2.4. Masson Staining. Similar to the procedure described in the section of H\&E staining, the paraffin section specimens were dewaxed using the conventional method with xylene, stained in hematoxylin solution for 5-10 min, washed with running water; subjected to $1 \%$ hydrochloric acid differentiation, rinsed with running water for a few minutes, immersed in Masson composite staining solution for 5$10 \mathrm{~min}$, washed with distilled water slightly, treated with $5 \%$ molybdophosphoric acid solution for approximately $5 \mathrm{~min}$, followed by direct counterstaining with aniline blue solution for $5 \mathrm{~min}$, treated with $1 \%$ glacial acetic acid for $1 \mathrm{~min}$, dehydrated with 95\% alcohol and absolute ethanol separately, rendered transparent using xylene, and sealed with neutral gum. The sections were observed under an optical microscope; the procedure for image acquisition was the same as that in the section of H\&E staining.

2.5. Periodic Acid-Schiff (PAS) Staining. The kidney tissues were fixed in Carnoy fixative solution at room temperature for $48 \mathrm{~h}$. The paraffin-embedded tissues were cut into $4 \mu \mathrm{m}$ sections, dewaxed, and washed with distilled water, oxidized with $1 \%$ periodic acid for $7 \mathrm{~min}$, washed with distilled water, and immersed in Schiff's solution for $7 \mathrm{~min}$ in a dark environment at room temperature. Next, they were rinsed with running water for $10 \mathrm{~min}$. The nucleus was lightly stained with alum hematoxylin staining solution for 2-3 minutes, slightly differentiated with $0.5 \%$ hydrochloric acid-alcohol solution after overstaining, rinsed with running water for
10 min, dehydrated with gradient ethanol, rendered transparent using xylene, and sealed with neutral gum. The sections were observed under an optical microscope; the procedure for image acquisition was same as that in Section of $\mathrm{H} \& \mathrm{E}$ staining.

2.6. Western Blotting (WB) and Immunohistochemical Staining (IHC). Western blotting was used to detect the expressions of proteins involved in the PI3K/Akt/mTOR signaling pathway and those associated with autophagy, inflammation, and apoptosis. Frozen kidney tissue was weighed and placed in a glass grinder. Next, $400 \mu \mathrm{L}$ of RIPA was added for every $50 \mathrm{mg}$ of kidney tissue to a lysis solution (containing $4 \mu \mathrm{L}$ of phosphatase inhibitor and $4 \mu \mathrm{L}$ of protease inhibitor); the supernatant was collected after centrifugation at $12000 \times \mathrm{g}$ for $30 \mathrm{~min}$. Total protein was extracted using the BCA protein quantitative method according to the instructions provided for the protein extraction kit (Boster, Wuhan, China). The concentration of each protein sample was adjusted to the same, and then $10 \mu \mathrm{L}$ of the sample was loaded into the gel for electrophoresis. The protein samples were separated by SDS-PAGE, and the proteins in the gel were electrically transferred to a polyvinylidene fluoride (PVDF) membrane. In 5\% bovine serum, the nonspecific blots in the membrane were blocked. The PVDF membrane was incubated with the antibody at $4^{\circ} \mathrm{C}$ overnight and then treated with the corresponding horseradish peroxidase secondary antibody (goat anti-rabbit AB20718) (Goat antimouse AB67 898). The membrane was incubated at room temperature for $30 \mathrm{~min}$ and then placed in an incubator for $1 \mathrm{~h}$. Next, images were recorded and analyzed after the membrane was washed (Tanon 5200). The main antibodies used were as follows: p-AKT (\#4060, working solutions, for IHC, $1: 1000)$, AKT (\#4691, IHC, $1: 300)$, p-mTOR (\#5536, IHC, 1:50), mTOR (\#2983, IHC, 1:100), and LC3 (\#83506, WB, 1:1000; IHC, 1:800) from Cell Signaling Technology (Danvers, MA, USA) and p-PI3K (ab182651, IHC, 1:200), PI3K (ab191606, IHC, 1:500), beclin-1 (ab207612, IHC1:200), p62 (ab56416, IHC, 1:800), caspase-3 (ab13847, IHC1:500), caspase-9 (ab52298, IHC, $1: 50$ ), IL-6 (ab9324, IHC, $1: 250$ ), IL-1 $\beta$ (ab9722, IHC, $1: 100)$, TNF-a (ab6671, IHC, $1: 100)$, and brain natriuretic peptide (BNP) (ab19645, IHC, $1: 1000)$ from Abcam (Cambridge, UK). For western blot results of LC3, two bands of LC3I and LC3II generated according to protocol from Cell Signaling Technology.

Kidney tissue specimens were fixed with $4 \%$ formaldehyde, rinsed with tap water for $5 \mathrm{~min}$, dehydrated with gradient ethanol, rendered transparent with xylene, and dipped and embedded in paraffin. The paraffin specimens were cut into $2 \mu \mathrm{m}$ sections. After the paraffin sections were dewaxed and washed with water, they were incubated with $3 \% \mathrm{H}_{2} \mathrm{O}_{2}$ and incubated at room temperature for $20 \mathrm{~min}$ to eliminate endogenous peroxidase activity. After washing them 3 times with distilled water, $50 \mu \mathrm{L}$ of primary antibody working solution was added to cover the tissue section. Next, the box was covered with a lid to prevent evaporation and incubated at room temperature for $60 \mathrm{~min}$. Subsequently, the sections were rinsed 3 times with PBS, treated with two 
drops of secondary antibody solution, incubated at room temperature for $30 \mathrm{~min}$, and rinsed thrice with PBS. They were stained using Dolichos biflorus agglutinin, incubated for $5 \mathrm{~min}$ at room temperature, and rinsed 3 times with PBS for $5 \mathrm{~min}$ each; 2 drops of hematoxylin solution were added into the tissue section. The sections were rinsed with running water after $5 \mathrm{~min}$ and then treated with $0.5 \%$ hydrochloric acid ethanol after approximately $10 \mathrm{sec}$, rinsed with tap water, dehydrated with gradient ethanol, rendered transparent with xylene, sealed with neutral gum, and observed under a light microscope. Six sliced section specimens were taken from each group; they were judged as positive by the appearance of clear light yellow/tan particles, and the dye signal in each selected glomerulus or tubulointerstitial region of the images was highlighted using Image Pro Plus quantitative software and quantified.

2.7. Data Analysis. Raw data was deposited in the reference [18]. Statistical analysis results were collected from three replicated independent experiments. Data are expressed as the mean \pm standard deviation (SD). For statistical comparison, a one-way analysis of variance (ANOVA) was performed on the parameter data. Statistical analysis was performed using GraphPad Prism 6 software (GraphPad, San Diego, California, USA). $p$ value was calculated by one-way analysis of variance or multiple $t$-test. $p<0.05$ was statistically significant.

\section{Results}

3.1. Effect of GLP Treatment on Blood Glucose and the Function of Kidney. Changes in the fasting blood glucose during the seventy-day experimental period were monitored weekly to assess the progress of diabetes. At end of experiment, serum glycated hemoglobin, $24 \mathrm{~h}$ urine protein, urea nitrogen, and serum creatinine were measured in order to assess the renal function. Rats with fasting blood glucose levels raised above $16.7 \mathrm{mmol} / \mathrm{L}$ after streptozotocin injection were used for the treatment with and without GLP. Compared to the diabetic group that was not administered treatment, the group administered GLP treatment showed significantly reduced fasting blood glucose at the ninth week till the end of experiment, even though it did not reach the normal level with GLP treatment alone (Table 1). At the end of the experiment, GLP treatment significantly decreased the level of glycated hemoglobin, $24 \mathrm{~h}$ urine protein, blood urea nitrogen, and serum creatinine, which were all significantly increased in the diabetic rats (Table 1). These changes indicate that GLP treatment could significantly improve the kidney function of the diabetic rats even though GLP could not reverse the increased biomarker levels back to normal.

\subsection{Effect of GLP Treatment on the Histology of Diabetic} Nephropathy. To further analyze the mechanism of GLP in the improvement of the renal function, pathological changes in the kidney specimens were examined by staining with $\mathrm{H} \& \mathrm{E}$, Masson, or PAS stains (Figures 1(a)-1(c)). The kidney extra- cellular matrix content via Masson staining (Figure 1(d)) and glycogen or mucin accumulation via PAS staining (Figure 1(e)) were analyzed. Compared to the control group, both were increased significantly in the diabetic group but were reduced significantly after GLP treatment.

The kidneys of the diabetic group that was not administered treatment showed hypertrophy through naked eye observation and felt harder in texture compared to those treated with GLP and the normal groups. In the micrograph of H\&E-stained specimens, the glomeruli and kidney tubules of the control group were seen clearly with normal histological structures. However, in the diabetic group, thickened glomerular basement membranes were observed; furthermore, the glomerular cavities were enlarged with irregular outline, the cells in the bulb were unevenly distributed, more degenerated fat was presented, some kidney tubules showed atrophy and collapse, and the cell walls were arranged irregularly (arrows indicate typical changes) (Figure 1(a)). Masson staining shows tubulointerstitial fibrosis (collagen fibers, blue) in the diabetic group. However, after GLP intervention, kidney tubular injury was significantly reduced, and mesangial matrix proliferation was significantly reduced (Figures 1(b) and 1(d)). The specimens stained with PAS showed that the glomerular basement membranes of the control group were intact and significantly reduced extracellular matrix depositions that were observed (Figures 1(c) and 1(e)). A large amount of glycogen deposition was observed in the diabetic group. In the tubules and glomeruli, the glomerular mesangial area was enlarged, and the extracellular matrix was significantly increased (the arrows indicate the typical changes). The above pathological changes were significantly improved in the GLP treatment group, and normal appearance was restored in these tissues.

Body weight in the diabetic group increased slowly, and it was significantly lower compared to the GLP treatment group at week 5; body weight increased continuously and significantly in the GLP treatment group after week 5 (Figure 2(a)), while the body weight increase was the lowest in the diabetic group during the entire experimental period. At end of experiment, both the weight of the kidney (Figure 2(b)) and the ratio of kidney weight to body weight (Figure 2(c)) in the diabetic group were significantly higher than that in the control group; however, this effect was significantly reversed by GLP treatment.

\subsection{Effect of GLP Treatment on the Level of A-SMA and BNP} Expression. The level of $\alpha$-SMA expression in the kidney tissue was assessed by western blotting (Figures 3(a) and 3(b)), while the level of BNP expression in the kidney tissues was assessed by immunohistochemical detection (Figures 3(d) and $3(\mathrm{c}))$. The results showed that the expression of both $\alpha$-SMA and BNP in the kidney tissues of diabetic rats increased significantly compared with that in the control group $(p<0.01)$; however, after GLP intervention, the expression level of both $\alpha$-SMA and BNP in the kidney tissues of diabetic rats decreased significantly, and the difference in these values between the diabetic+GLP group and the diabetic group was statistically significant $(p<0.01)$. 
TABLE 1: The biochemical indices in different groups at end of experiment, day 70 .

\begin{tabular}{lcccc}
\hline Group & Control & Diabetic & Diabetic+GLP & Improvement rate^ (\%) \\
\hline Fasting blood glucose $(\mathrm{mmol} / \mathrm{L})$, day 0 & $4.56 \pm 0.34$ & $17.10 \pm 1.34^{\# \#}$ & $17.77 \pm 1.28^{\# \#}$ & \\
Fasting blood glucose $(\mathrm{mmol} / \mathrm{L})$, day 70 & $4.87 \pm 0.27$ & $23.10 \pm 1.59^{\# \#}$ & $19.98 \pm 0.98^{\# \# *}$ & 13.51 \\
Glycated hemoglobin $(\mathrm{g} / \mathrm{L})$ & $1.65 \pm 0.10$ & $2.42 \pm 0.08^{\#}$ & $2.03 \pm 0.08^{\# \# *}$ & 16.12 \\
24 h urine protein $(\mathrm{mg} / \mathrm{L})$ & $184.6 \pm 21.06$ & $372.3 \pm 34.57^{\# \#}$ & $244.5 \pm 32.29^{\# *}$ & 34.33 \\
Blood urea nitrogen $(\mathrm{mmol} / \mathrm{L})$ & $4.40 \pm 0.48$ & $8.44 \pm 0.68^{\# \#}$ & $6.70 \pm 0.63^{\# *}$ & 20.62 \\
Serum creatinine $(\mu \mathrm{mol} / \mathrm{L})$ & $25.17 \pm 1.72$ & $38.00 \pm 3.74^{\#}$ & $31.00 \pm 1.41^{\# \# *}$ & 18.42 \\
\hline
\end{tabular}

Note: data expressed as the mean \pm standard deviation, $n=6$ in each group. ${ }^{\wedge}$ Improvement rate was calculated by (diabetic - diabetic - GLP)/diabetic $\times 100 \%$; ${ }^{\#} p<0.05,{ }^{\# \#} p<0.01$, compared with the control group; ${ }^{*} p<0.05$, compared with the diabetic group using Tukey's test. Control: $5 \mathrm{ml} / \mathrm{kg}$ saline (p.o.); diabetic: $50 \mathrm{mg} / \mathrm{kg}$ streptozotocin (intraperitoneal) and $5 \mathrm{ml} / \mathrm{kg}$ saline (p.o.); diabetic+GLP: $50 \mathrm{mg} / \mathrm{kg}$ streptozotocin (intraperitoneal) and $300 \mathrm{mg} / \mathrm{kg}$ Ganoderma lucidum polysaccharides (GLP) (p.o.).

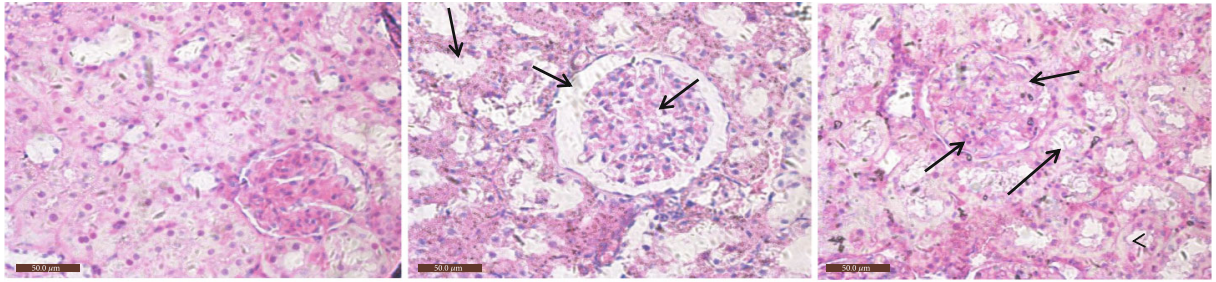

(a)

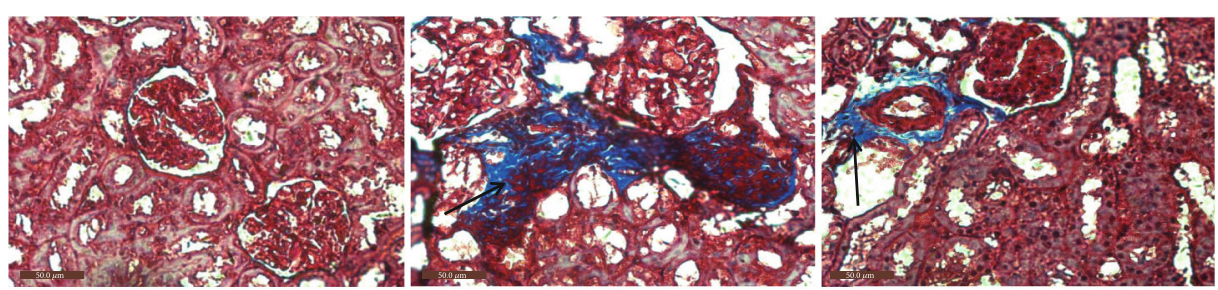

(b)

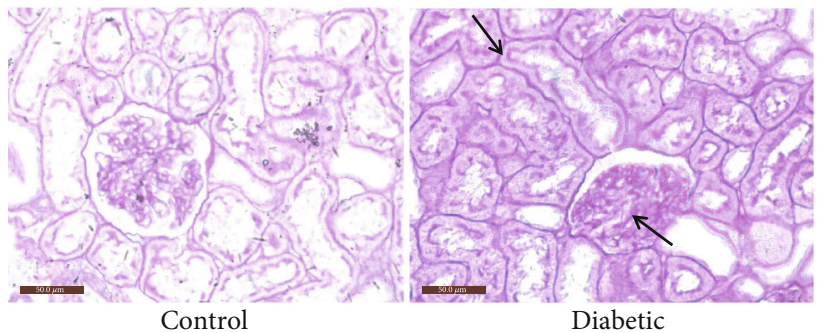

(c)

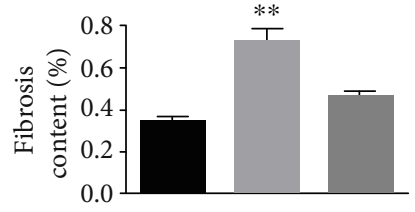

(d)

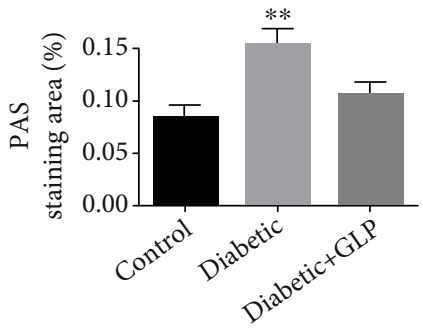

(e)

FIgURe 1: Pathological changes in the kidney tissue of diabetic rats. Representative images showing kidney tissue sections after (a) hematoxylin and eosin, (b) Masson's trichrome, and (c) periodic acid-Schiff staining (PAS). Quantitative results for (d) collagen accumulation assessed using Masson's trichrome staining and (e) extracellular matrix accumulation assessed using PAS staining for the different groups (original magnification $\times 400$ ). The arrow in the kidney section in the diabetic group ((a), middle) indicates the irregularly arranged cell membranes, disturbed structures, disappeared nucleus, or unclear intercellular boundary. The arrow in the middle image of (b) indicates considerable deposition of collagen fibers, and the arrow in middle image of (c) indicates considerable deposition of reactive glycogen. Values are presented as the mean \pm SE; $n=4$ per group. ${ }^{* *} p<0.01$ versus either the control group or the diabetic+GLP group using Tukey's test. Control: $5 \mathrm{ml} / \mathrm{kg}$ saline (p.o.); diabetic: $50 \mathrm{mg} / \mathrm{kg}$ streptozotocin (intraperitoneal) and $5 \mathrm{ml} / \mathrm{kg}$ saline (p.o.); diabetic+GLP: $50 \mathrm{mg} / \mathrm{kg}$ streptozotocin (intraperitoneal) and $300 \mathrm{mg} / \mathrm{kg}$ Ganoderma lucidum polysaccharides (GLP) (p.o.).

3.4. Effect of GLP Treatment on the PI3K/Akt/mTOR Signaling Pathway. The level of p-PI3K, p-Akt, and pmTOR expression in the kidney tissue was assessed by immunohistochemical detection (Figures 4(a) and 4(b)), respectively. The expression of $\mathrm{p}$-PI3K, $\mathrm{p}$-Akt, and $\mathrm{p}$ -
mTOR in the kidney tissue of the diabetic group was significantly increased compared with that of the normal group $(p<0.01)$. The expressions of these proteins in the kidney tissues of diabetic rats were significantly reduced after GLP intervention $(p<0.01)$. 


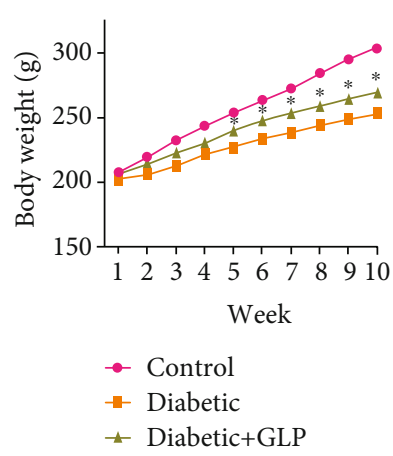

(a)

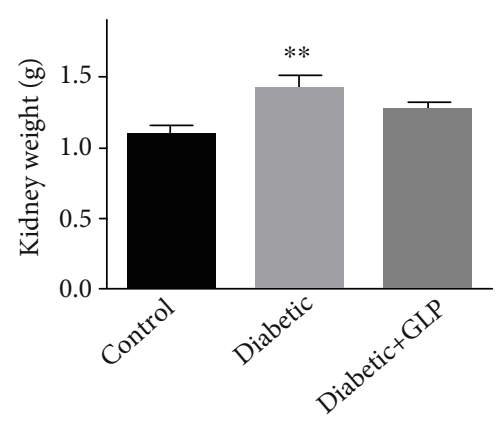

(b)

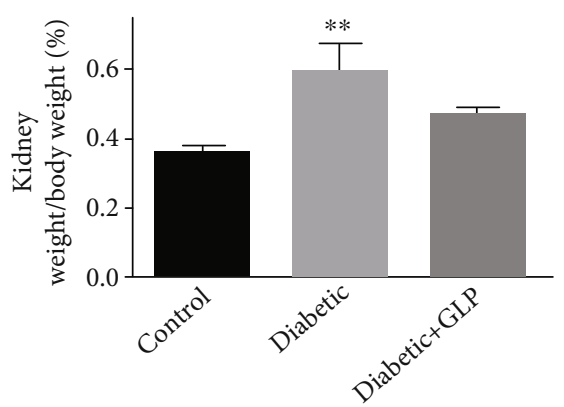

(c)

FIGURE 2: Body weight changes during the experimental period (a) and kidney weight (b) and kidney weight/body weight (\%) (c) at the end of the experiment at day 70 . Values are presented as the mean \pm SE; $n=8$ per group. ${ }^{*}$ compared to the control, both diabetic and diabetic + GLP shows $p<0.05$ in (a). In (b) and (c), ${ }^{* *}$ indicates $p<0.01$ versus either the control group or the diabetic +GLP group using Tukey's test. Control: $5 \mathrm{ml} / \mathrm{kg}$ saline (p.o.); diabetic: $50 \mathrm{mg} / \mathrm{kg}$ streptozotocin (intraperitoneal) and $5 \mathrm{ml} / \mathrm{kg}$ saline (p.o.); diabetic+GLP: $50 \mathrm{mg} / \mathrm{kg}$ streptozotocin (intraperitoneal) and $300 \mathrm{mg} / \mathrm{kg} \mathrm{GLP} \mathrm{(p.o.).}$

\subsection{Effect of GLP Treatment on the Expression LC3-II/LC3-I,} Beclin-1, and P62. The immunohistochemical results of beclin-1, LC3, and P62 were shown in Figure 5(a), and the LC3 was further analyzed by western blot to see the subtype of LC3-II and LC3-I expression, which were shown in Figure 5(c). Compared with the control group, the expression of both beclin-1 and LC3 as well as the ratio of LC3II/LC3-I in the kidney tissue of the diabetic group was significantly decreased, and the expression of P62 was significantly increased $(p<0.01)$. However, after GLP intervention, beclin-1 and LC3 as well as the ratio of LC3II/LC3-I were all significantly increased, and the expression of P62 was significantly reduced $(p<0.01)$.

3.6. Effect of GLP Treatment on the Expression of Caspase-3 and Caspase-9. The western blot and immunohistochemical results of caspase- 3 and caspase-9 were shown in Figures 6(a) and 6(b). Results show that the expression of caspase- 3 and caspase- 9 in kidney tissues of the diabetic group was significantly increased compared with the control group $(p<0.01)$; however, after GLP intervention, their expressions in the kidney tissues were reduced significantly $(p<0.01)$.

3.7. Effect of GLP Treatment on the Expression of TNF- $\bigotimes, I L-$ 6 , and $I L-1 \beta$. The immunohistochemical results of the expression of IL-6, IL- $1 \beta$, and TNF-a were shown in
Figure 7. In the diabetic group, they were significantly increased compared with the control group $(p<0.01)$; however, after GLP intervention, their expressions were significantly reduced $(p<0.01)$.

\section{Discussion}

Diabetic nephropathy is the most common serious complication of diabetes. It occurs in diabetic patients with a long course, severe illness, and hypertension [19]. Once a large amount of proteinuria occurs, renal function will irreversibly decline progressively and eventually develop into end-stage renal disease. According to statistics, approximately 20$30 \%$ of diabetic patients clinically developed diabetic nephropathy [20], and diabetic nephropathy developed into end-stage renal disease, a critical disease, in $20-40 \%$ of patients. In China, some traditional Chinese medicines have been recommended to treat diabetic nephropathy $[21,22]$.

The main pathological features of diabetic nephropathy are glomerular hypertrophy, widened mesangial matrix, and development of fibrosis or sclerosis. The early symptom is the appearance of trace proteinuria, which can lead to kidney damage and failure upon further clinical progression of the disease [23]. Therefore, the production of proteinuria indicates impairment of the structure and function of the glomerular filtration membrane or damaged renal reabsorption. This study found that the $24 \mathrm{~h}$ urinary protein, serum 


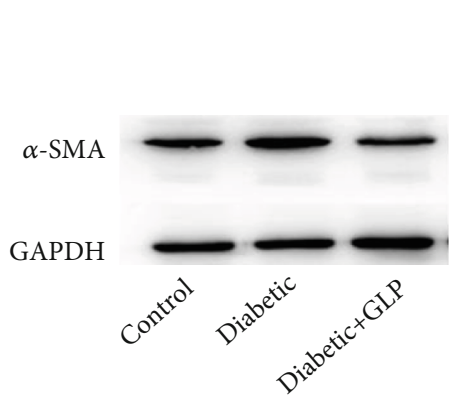

(a)

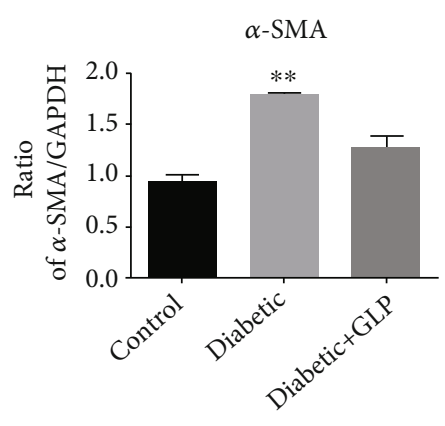

(b)

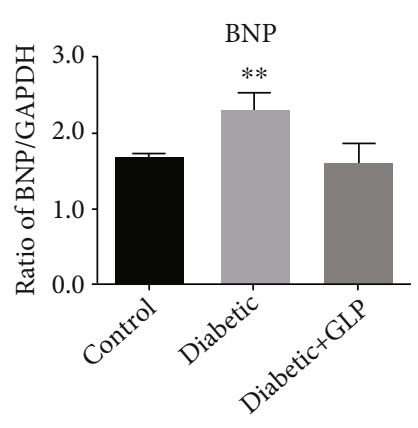

(c)

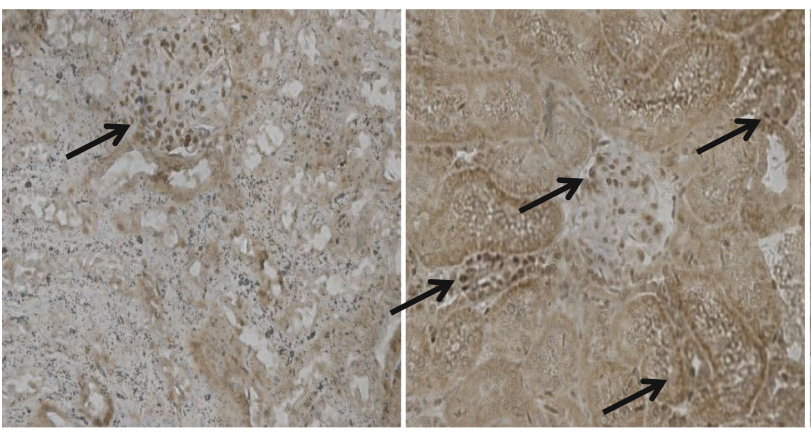

Control
Diabetic

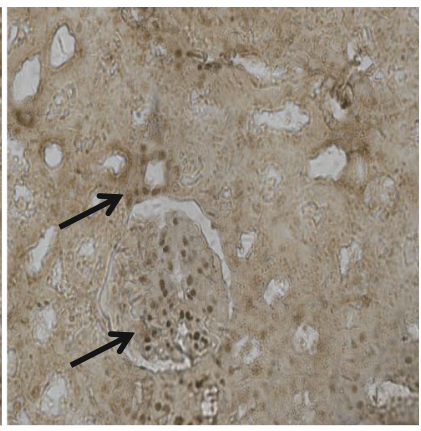

Diabetic+GLP

(d)

Figure 3: Effect of Ganoderma lucidum polysaccharide (GLP) on the protein expressions of $\alpha$-SMA (molecular weight, $42 \mathrm{kDa}$ ) assessed by western blot and brain natriuretic peptide (BNP) for immunohistochemical analysis in the kidney tissues of rats from different groups. Micrographs, (d), original magnification $\times 400$; (c) statistic analysis. Representative western blot images (a) and quantitative analysis (b) for expression of $\alpha$-SMA (d) Representative immunohistochemistry micrographs for BNP expression. Strong BNP immunostaining was observed in almost all kidney cells in the diabetic group, compared with the control and diabetic+GLP groups. (c) Statistical analysis of immunohistochemistry results for the renal BNP expression. The arrows in the kidney section in the diabetic group indicate BNP highly expressed areas. In control and treatment groups, BNPs are mainly expressed in the glomerular areas, but there are higher expression in the tubule area in the diabetic group. Values are expression rate represent the mean $\pm \mathrm{SE} ; n=3$ in each group. ${ }^{* *} p<0.01$ versus the control group and the diabetic+GLP group using Tukey's test. Control: $5 \mathrm{ml} / \mathrm{kg}$ saline (p.o.); diabetic: $50 \mathrm{mg} / \mathrm{kg}$ streptozotocin (i.p.) and $5 \mathrm{ml} / \mathrm{kg}$ saline (p.o.); diabetic+GLP: $50 \mathrm{mg} / \mathrm{kg}$ streptozotocin (i.p.) and $300 \mathrm{mg} / \mathrm{kg}$ GLP (p.o.).

creatinine and blood urea nitrogen in diabetic rats were significantly higher than that in the control group. Compared to the diabetic group, they were decreased by $35 \%, 18 \%$, and $21 \%$, respectively, after GLP treatment, which showed clearly improvement, even though these indices were unable to reach the normal level in the control group (Table 1). These improvements were partly caused by the decrease of fasting blood glucose and glycated hemoglobin by $14 \%$ and $16 \%$, respectively. A human study showed an increased $1 \%$ of $\mathrm{HbAlc}$ which would increase 3 grams (95\% CI: 1.5-4.6 grams) heart left ventricle mass which highly affects blood circulation and links to the kidney diseases [24]. In one study [15], GLP (250 mg/kg) could slow down the progression of streptozotocin-induced diabetic nephropathy in mice by decrease blood glucose and triglyceride levels, suggesting the metabolic modulation of GLP. This was also supported by our histological results which kidney tubular epithelial cells were shed, and vacuole degeneration was detected by kidney tissue staining. Inflammatory cells extensively infiltrated the kidney interstitium, kidney tubular hypertrophy and globules were significantly enlarged, the mesangial area was enlarged, and the extracellular matrix was significantly increased. The results were the same as that of previous studies [25]. GLP treatment can maintain a relatively normal structure and the function of kidneys in diabetic rats. In addition, reversal of pathological changes, as observed through H\&E, PAS, and Masson staining, suggests that GLP can ameliorate the damaged and pathologically altered kidney tissue. Li et al. [16] showed that GLP (100, 200, and $400 \mathrm{mg} / \mathrm{kg}$ ) treatment improved streptozotocin-induced diabetic nephropathy and reversed the decreased matrix metalloproteinase-2/tissue inhibitor of metalloproteinase-2 in rats. This further decreased the accumulation of extracellular matrix, suggesting the renoprotective effect of GL-PS through rebalance matrix metalloproteinase-2/tissue inhibitor of metalloproteinase-2.

BNP is a substance composed of 32 amino acids, and it performs multiple functions. It can increase the excretion of sodium from the kidney by acting on the guanylate cyclase receptor, inhibit the sympathetic central nervous system activity and the renin-angiotensin aldosterone system, relax the vascular smooth muscle, and increase endothelial permeability. Recent studies [26] have shown that BNP can inhibit cardiac and vascular remodeling. Another finding 


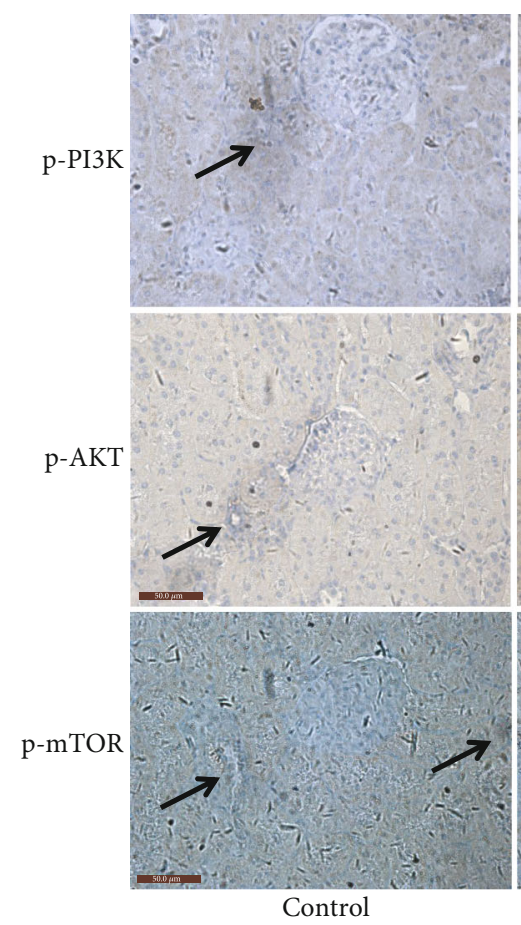

Control
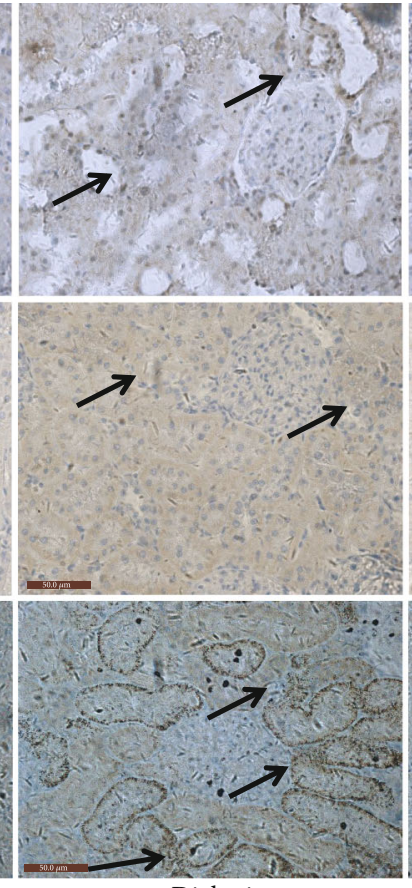

Diabetic
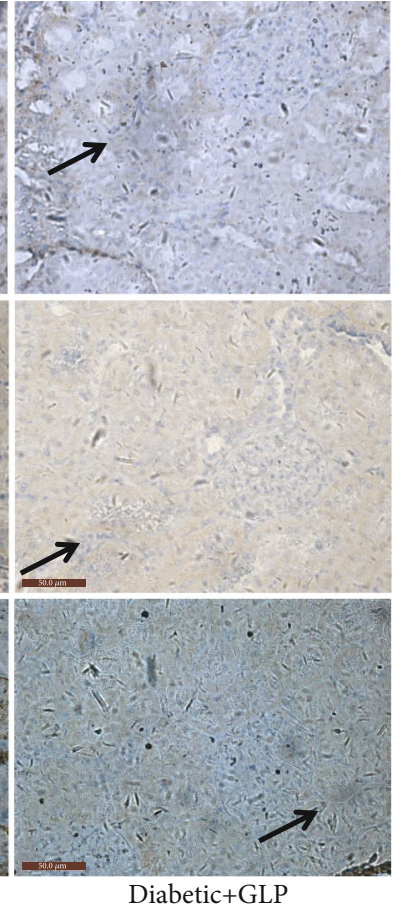

Diabetic+GLP

(a)
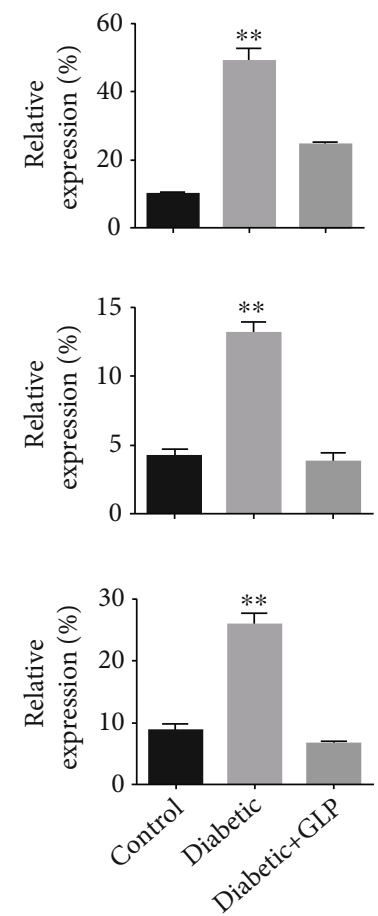

(b)

FIGURE 4: Effect of Ganoderma lucidum polysaccharide (GLP) on the protein expression of p-PI3K, p-Akt, and p-mTOR according to immunohistochemical results (a) and their statistical analysis (b) in renal tissues in different groups. (a) micrographs, magnification $\times 400$. Arrows indicate the changed areas. Values represent the mean \pm SE; $n=3$ in each group. ${ }^{* *} p<0.01$ versus the control group and the diabetic+GLP group using Tukey's test. Control: $5 \mathrm{ml} / \mathrm{kg}$ saline (p.o.); diabetic: $50 \mathrm{mg} / \mathrm{kg}$ streptozotocin (i.p.) and $5 \mathrm{ml} / \mathrm{kg}$ saline (p.o.); diabetic+GLP: $50 \mathrm{mg} / \mathrm{kg}$ streptozotocin (i.p.) and $300 \mathrm{mg} / \mathrm{kg}$ GLP (p.o.).

[27] showed that BNP increased the risk of renal function in patients with type 2 diabetes. Researches on patients with diabetic nephropathy $[28,29]$ showed that BNP increased, especially at the early stage of diabetic nephropathy. When fibroblasts transform into myofibroblasts, there is an increase in $\alpha$-SMA expression, migration, and proinflammatory signals and the production of proteins that reshape the extracellular matrix [30]. Meroterpenoids from Ganoderma cochlear, cochlearols A and B and polycyclic meroterpenoids, exerted renoprotectivity by inhibiting the expression of renal fibrosis related markers such as collagen I, fibronectin, and $\alpha$-SMA in a dose-dependent manner $(5,10$, and $20 \mu \mathrm{M})$ [31]. The decreased expression of BNP and $\alpha$-SMA after GLP treatment indicates that GLP plays an important role in kidney protection. This observation was confirmed through the assessment of H\&E staining, Masson staining, and PAS staining, which showed that pathological changes in the kidney and kidney fibrosis in diabetic rats were significantly reduced after the GLP treatment.

In terms of the mechanism, PI3K, Akt, and mTOR are considered to play key roles in the insulin signalling pathway, which regulates glucose uptake and glycogen synthesis [32]. In recent years, the role of the PI3k/Akt/mTOR signaling pathway in the development of diabetic nephropathy has received increasing attention. Lu et al. [33] reported that the activation of the PI3k/Akt/mTOR signaling pathway can accelerate the occurrence and deterioration of kidney fibrosis in diabetic rats. This study found that compared with the control group, the expression of p-PI3K, p-Akt, and pmTOR increased in the diabetic group had significantly decreased after GLP treatment, indicating that GLP may improve diabetic nephropathy by inhibiting the PI3k/Akt/ mTOR signaling pathway. Fibrosis of diabetic nephropathy tissue is consistent with the results from previous studies. $\mathrm{PI} 3 \mathrm{k} / \mathrm{Akt} / \mathrm{mTOR}$ is a very important signaling pathway that regulates cell autophagy. It plays an important role in the signal regulation and molecular mechanism of autophagy. This pathway is also key in other important cellular processes, such as cellular survival, appreciation, growth, and differentiation [34]. The PI3k/Akt/mTOR signaling pathway is currently known as the only inhibitory pathway for autophagy, and its activation can inhibit autophagy. Zhong et al. [35] found that ligustrazine can inhibit the expression of $\mathrm{p}$-PI3K, p-Akt, and p-mTOR in the kidney tissues of diabetic rats, thereby, increasing the expression level of the autophagy marker protein $\mathrm{LC} 3 \mathrm{~B}$ and the ratio of LC3B-II/ LC3B-I. The results of this experiment indicate that the $\mathrm{PI} 3 \mathrm{k} / \mathrm{Akt} / \mathrm{mTOR}$ signaling pathway is activated, and autophagy is inhibited in diabetic nephropathy; however, the signaling pathway is inhibited, and autophagy is reactivated after GLP treatment, indicating that GLP plays a renal protective role. The mechanism may be related to its inhibition of the PI3k/Akt/mTOR signaling pathway, which in turn promotes kidney autophagy.

According to previous research, the apoptosis of kidney cells plays an important role in the occurrence and 


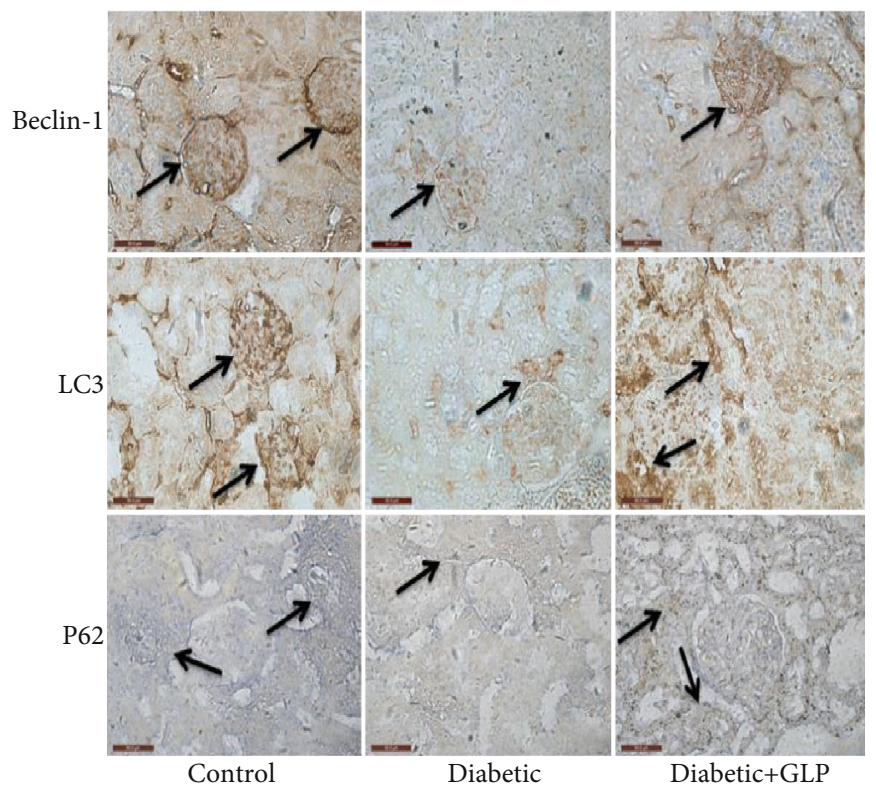

(a)
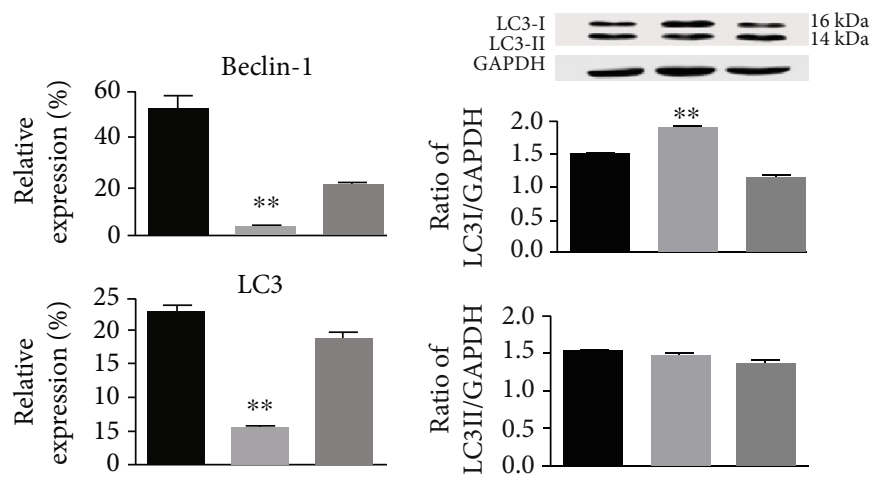

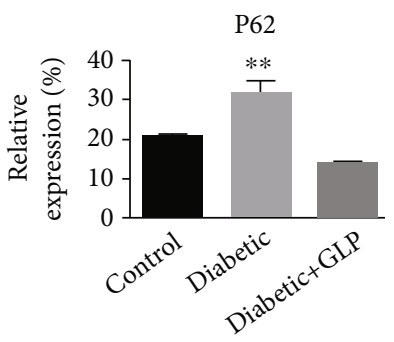

(b)

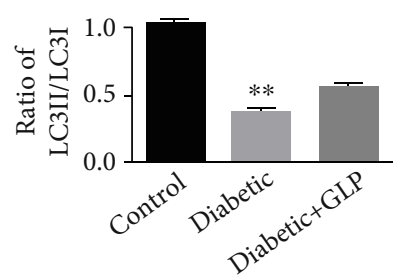

(c)

FIGURE 5: Effect of Ganoderma lucidum polysaccharide (GLP) on the expression of beclin-1, LC3, and P62 ((a) immunohistochemical micrographs and (b) their statistical analysis) as well as the LC3-I and II (western blot results, (c)). (a) micrographs, magnification $\times 400$. Arrows indicate the changed areas. Values in (b) and (c) represent the mean \pm SE; $n=3$ in each group. ${ }^{* *} p<0.01$ versus the control group and the diabetic+GLP group using Tukey's test. Control: $5 \mathrm{ml} / \mathrm{kg}$ saline (p.o.); diabetic: $50 \mathrm{mg} / \mathrm{kg}$ streptozotocin (i.p.) and $5 \mathrm{ml} / \mathrm{kg}$ saline (p.o.); diabetic+GLP: $50 \mathrm{mg} / \mathrm{kg}$ streptozotocin (i.p.) and $300 \mathrm{mg} / \mathrm{kg}$ GLP (p.o.).

development of diabetic nephropathy. In recent years, increasing evidence shows that there is an interactive effect between apoptosis and cell autophagy, and that the two are interrelated and mutually regulated. When diabetic nephropathy is stimulated by factors such as high glucose, podocytes can not only discard proteins and organelles through autophagy but also undergo apoptosis. The activities of autophagy and apoptosis may vary during different periods. A literature review to understand the relationship between the two revealed the following two aspects: autophagy involves autophagy genes, e.g., ce, which is upstream of the apoptosis process; these genes initiate apoptosis, and their expression affects the degree of apoptosis [36]. Autophagy can maintain the stability of the cell environment and inhibit apoptosis through multiple pathways [37]. Studies have found that normal autophagy plays an important role in reducing the cerebral ischemia-reperfusion injury via inhibition of apoptosis, while an abnormally high level of 


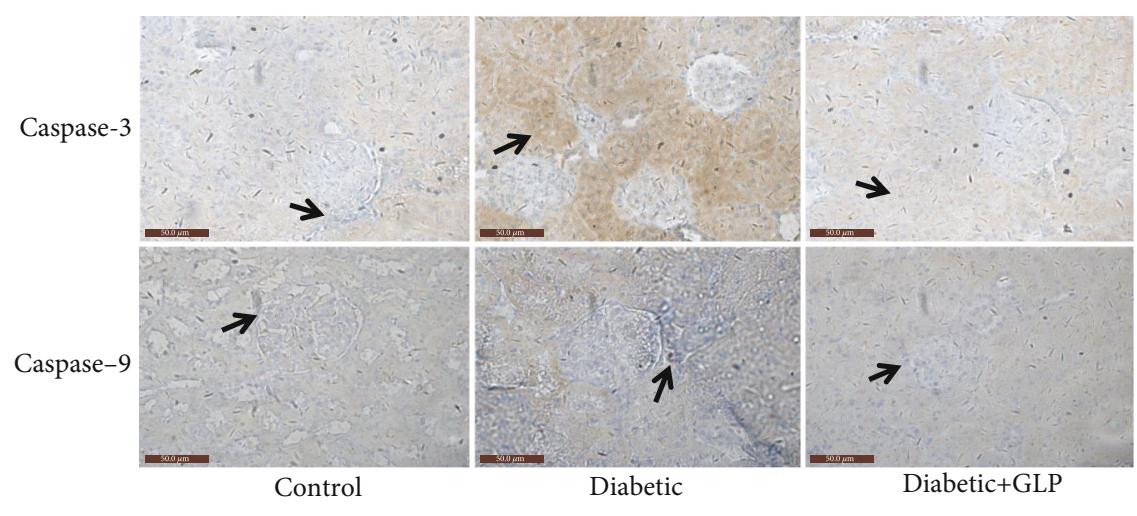

(a)

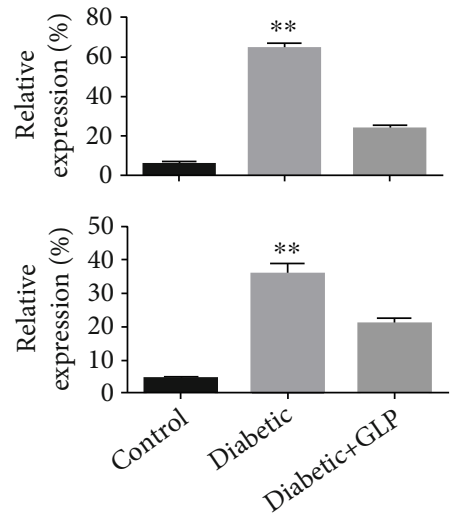

(b)

FIgURE 6: Effect of Ganoderma lucidum polysaccharide (GLP) on the protein expression of caspase-3 and -9 in renal tissues according to immunohistochemical micrographs ((a) magnification $\times 400$, arrows indicate the changed areas) and statistical analysis (b). Values represent the mean $\pm \mathrm{SE} ; n=3$ in each group. ${ }^{* *} p<0.01$ versus the control group and the diabetic+GLP group using Tukey's test. Control: $5 \mathrm{ml} / \mathrm{kg}$ saline (p.o.); diabetic: $50 \mathrm{mg} / \mathrm{kg}$ streptozotocin (i.p.) and $5 \mathrm{ml} / \mathrm{kg}$ saline (p.o.); diabetic+GLP: $50 \mathrm{mg} / \mathrm{kg}$ streptozotocin (i.p.) and $300 \mathrm{mg} / \mathrm{kg}$ GLP (p.o.).

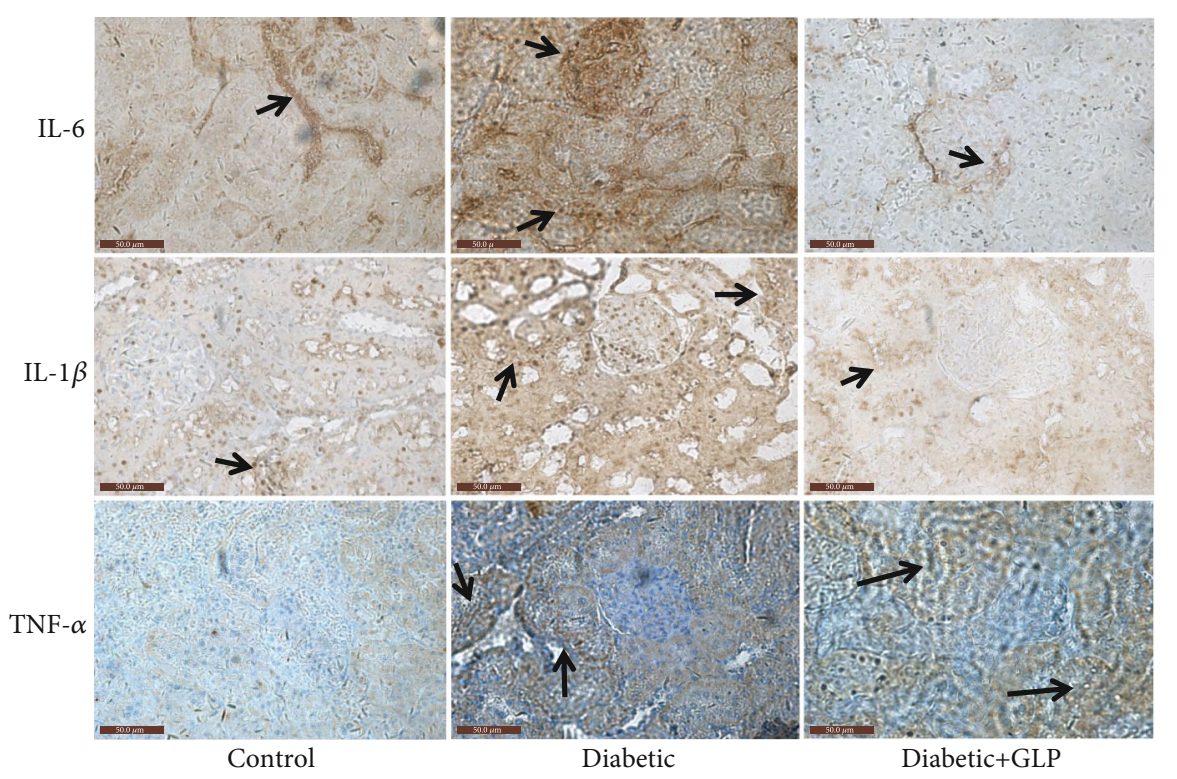

(a)
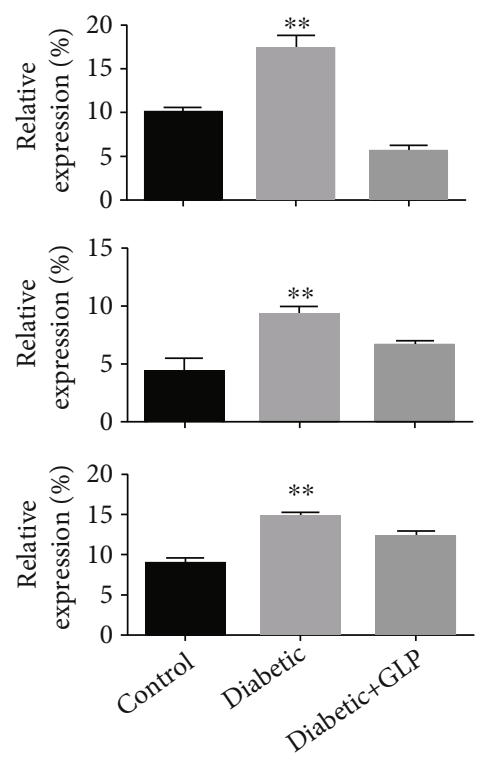

(b)

FIGURE 7: Effect of Ganoderma lucidum polysaccharide (GLP) on the protein expression of IL-6, IL-1 $\beta$, and TNF-a in renal tissues according to immunohistochemical micrographs ((a) magnification $\times 400$, arrows indicate the changed areas) and statistical analysis (b). Values are presented as the mean $\pm \mathrm{SE}, n=3$ in each group; ${ }^{* *} p<0.01$, compared with either the control group or diabetic+GLP group using Tukey's test. Control: $5 \mathrm{ml} / \mathrm{kg}$ saline (p.o.); diabetic: $50 \mathrm{mg} / \mathrm{kg}$ streptozotocin (i.p.) and $5 \mathrm{ml} / \mathrm{kg}$ saline (p.o.); diabetic+GLP: $50 \mathrm{mg} / \mathrm{kg}$ streptozotocin (i.p.) and $300 \mathrm{mg} / \mathrm{kg}$ GLP (p.o.).

autophagy can aggravate this injury [38]. Another example of the protective effect of autophagy is demonstrated in intervertebral disc degeneration; activation of autophagy inhibits the degradation of the extracellular matrix of the endplate chondrocytes via inhibition of apoptosis [39]. In terms of apoptosis, autophagy is indispensable, but the typical apoptosis inhibitory proteins, e.g., Bcl-2, can affect this process [40]. The results of this experiment also showed that the expression of the apoptosis-related proteins caspase- 3 and caspase- 9 increased in the diabetic group and decreased after treatment with GLP, indicating that GLP can activate autophagy, play an antiapoptotic effect, and improve damaged kidney tissue. Autophagy is an innate immune mechanism that can kill pathogens and control inflammation. Autophagy reduces pathogen burden and participates in the processing of antigens to activate adaptive immunity [41]. In recent years, increasing studies have shown that the inflammatory process may play an important role in the pathogenesis of diabetic nephropathy, and adhesion molecules, inflammatory chemokines, and inflammatory factors play specific roles in the development of diabetic nephropathy [42]. Autophagy can negatively regulate 
inflammatory factors. Lipopolysaccharide (LPS) stimulates the expression levels of IL- $1 \beta$ and IL- 8 in mice in which the key autophagy gene Atg16L1 was knocked out [43]. In addition, autophagy can reduce the occurrence of inflammation by regulating the composition and activation of inflammatory bodies via regulating the secretion of proinflammatory factors such as IL-1 $\beta$ and IL-18 [44]. Kimura et al. [45] showed that renal tubules are one of the most active areas of inflammatory response in chronic kidney injury. Autophagy can effectively reduce damaged and dysfunctional mitochondria by removing damage-related molecules and abnormal lysosomes. Subsequently, this process inhibits the inflammatory response and improves immunoregulation, resulting in protection of renal function. Ma et al. [46] reported that a specific dose of GLP induces a significant effect on diabetic nephropathy, and the mechanism underlying this effect may be through inhibiting the activation of NF- $\kappa \mathrm{B} / \mathrm{NLRP} 3$ inflammatory bodies, reducing the inflammatory response, and improving renal function, thus restoring the biochemical indicators of diabetes in the blood and urine of mice with nephropathy. Patients with diabetic nephropathy have elevated IL-6, and patients with dominant proteinuria have higher serum albumin levels than patients with microalbuminuria or normal albuminuria [47]. Studies have found [48] that the expression of TNF- $\alpha$ is significantly increased in the kidneys of rats with type I diabetes. TNF- $\alpha$, as a key factor that mediates the inflammatory response, can induce an adhesion effect in glomerular endothelial cells. Inflammatory substances cause an increase in the mesangial matrix and mesangial cell proliferation, destroying the glomerular structure [49]. Several extracts of Ganoderma lucidum showed amelioration in this progress in a review [50], e.g., one study [51] showed that proteoglycan isolated from Ganoderma lucidum fruiting bodies shows protection renal morphology in diabetic mice in a dosedependently $(75,250$, and $450 \mathrm{mg} / \mathrm{kg})$ manner during a 8 week treatment. According to previous research, the mechanism appears also via directly elimination reactive oxygen species, suppresses lipid peroxidation, and indirectly scavenges the radicals via activating antioxidant enzyme systems and chelation with metal ion by forming crossbridge between carboxyl groups decreasing reactive oxygen species generation [52-60]. This study showed that the expressions of the inflammatory factors IL-6, IL- $1 \beta$, and TNF- $\alpha$ in the diabetic group were significantly increased, while they were reduced significantly after GLP treatment.

\section{Conclusion}

In summary, these results indicate that GLP produces a significant protective effect in diabetic nephropathy by reducing the renal pathological damage and decreasing blood glucose and glycated hemoglobin and improves the kidney function indicated by decreasing the levels of serum creatinine, blood urea nitrogen, and $24 \mathrm{~h}$ urine protein as well as the renal $\alpha$-SMA and BNP expressions and even more GLP increased body weight and kidney weight. GLP inhibited the PI3K/Akt/mTOR signaling pathway and inhibited apoptosis indicators of both caspase- 3 and -9 expression.
These may be contributed by the activation of autophagy via stimulation beclin-1, LC3-II/LC-I, and reduction the expression of p62. These changes may be used partly to explain the molecular mechanism of GLP on alleviation kidney tissue fibrosis. These effects indicate the potential application of GLP for the treatment of diabetic nephropathy.

\section{Abbreviations}

GLP: $\quad$ Ganoderma lucidum polysaccharides

mTOR: Mammalian target of rapamycin

p-Akt: Phosphorylated protein kinase B

PAS: $\quad$ Periodic acid-Schiff staining

PI3K: Phosphoinositide 3 kinase

LC3: $\quad$ Cytoplasmic light chain 3

TNF-a: Tumor necrosis factor-alpha.

\section{Data Availability}

The data are available here: https://data.mendeley.com/ datasets/xf58rsgj94/1 doi:10.17632/xf58rsgj94.1.

\section{Conflicts of Interest}

The authors have declared no conflict of interest.

\section{References}

[1] D. Sharma, P. Bhattacharya, K. Kalia, and V. Tiwari, "Diabetic nephropathy: new insights into established therapeutic paradigms and novel molecular targets," Diabetes Research and Clinical Practice, vol. 128, pp. 91-108, 2017.

[2] C. Magee, D. J. Grieve, C. J. Watson, and D. P. Brazil, "Diabetic nephropathy: a tangled web to unweave," Cardiovascular Drugs and Therapy, vol. 31, pp. 579-592, 2017.

[3] M. J. Yahya, P. B. Ismail, N. B. Nordin et al., "Association of CCL2, CCR5, ELMO1, and IL8 polymorphism with diabetic nephropathy in Malaysian type 2 diabetic patients," International journal of chronic diseases, vol. 2019, Article ID 2053015, 13 pages, 2019.

[4] N. B. Flemming, L. A. Gallo, and J. M. Forbes, "Mitochondrial dysfunction and signaling in diabetic kidney disease:oxidative stress and beyond," Seminars in Nephrology, vol. 38, no. 2, pp. 101-110, 2018.

[5] H. Yang, T. Xie, D. Li et al., "Tim-3 aggravates podocyte injury in diabetic nephropathy by promoting macrophage activation via the NF- $\kappa \mathrm{B} / \mathrm{TNF}-\alpha$ pathway," Molecular Metabolism, vol. 23, pp. 24-36, 2019.

[6] X. Cai, W. He, and G. Yang, "Research progress on the biological activity of Ganoderma lucidum polysaccharides," Edible Fungi, vol. 40, no. 3, pp. 1-4, 2018.

[7] X. Gong, M. Ji, J. Xu, C. Zhang, and M. Li, "Hypoglycemic effects of bioactive ingredients from medicine food homology and medicinal health food species used in China," Critical Reviews in Food Science and Nutrition, vol. 60, no. 14, pp. 2303-2326, 2020.

[8] B. Wei, R. Zhang, J. Zhai et al., "Suppression of Th17 Cell Response in the Alleviation of Dextran Sulfate SodiumInduced Colitis by Ganoderma lucidum Polysaccharides," Journal of Immunology Research, vol. 2018, Article ID 2906494, 10 pages, 2018. 
[9] K. X. Zhu, S. Nie, C. Li, D. Gong, and M. Y. Xie, "Ganoderma atrum polysaccharide improves aortic relaxation in diabetic rats via PI3K/Akt pathway," Carbohydrate Polymers, vol. 103, pp. 520-527, 2014.

[10] Y. Ma, F. Chen, S. Yang, Y. Duan, Z. Sun, and J. Shi, “Silencing of TRB3 ameliorates diabetic tubule interstitial nephropathy via PI3K/Akt signaling in rats," Medical Science Monitor, vol. 23, pp. 2816-2824, 2017.

[11] X. Shao, D. Lai, L. Zhang, and H. Xu, "Induction of Autophagy and Apoptosis via PI3K/AKT/TOR Pathways by Azadirachtin A in Spodoptera litura Cells," Scientific Reports, vol. 6, no. 1, article 35482, 2016.

[12] M. Long and T. G. McWilliams, "Monitoring autophagy in cancer: from bench to bedside," Seminars in cancer biology, vol. 66, pp. 12-21, 2020.

[13] W. Wei, X. R. An, S. J. Jin, X. X. Li, and M. Xu, "Inhibition of insulin resistance by PGE1 via autophagy dependent FGF21 pathway in diabetic nephropathy," Scientific Reports, vol. 8, p. 9, 2018.

[14] Y. Moriwaki, T. Yamamoto, Y. Shibutani et al., "Elevated levels of interleukin-18 and tumor necrosis factor- $\alpha$ in serum of patients with type 2 diabetes mellitus: Relationship with diabetic nephropathy," Metabolism, vol. 52, no. 5, pp. 605-608, 2003.

[15] C. Y. He, W. D. Li, S. X. Guo, S. Q. Lin, and Z. B. Lin, "Effect of polysaccharides fromGanoderma lucidumon streptozotocininduced diabetic nephropathy in mice," Journal of Asian Natural Products Research, vol. 8, no. 8, pp. 705-711, 2006.

[16] W. Li, C. Mao, and Q. Yin, "Effects of Ganoderma lucidum polysaccharides on the expression of matrix metalloproteinase-2/tissue inhibitor of metalloproteinase-2 in diabetic rat kidney," Chinese Journal of Gerontology, vol. 3, pp. 226-229, 2008.

[17] S. Wu, "Hypolipidaemic and anti-lipidperoxidant activities of Ganoderma lucidum polysaccharide," International journal of biological macromolecules, vol. 118, no. Part B, pp. 20012005, 2018.

[18] https://data.mendeley.com/datasets/xf58rsgj94/1.

[19] Y. Li, R. Miao, Y. Liu et al., "Efficacy and safety of tripterygium glycoside in the treatment of diabetic nephropathy: a systematic review and meta-analysis based on the duration of medication," Front Endocrinol (Lausanne), vol. 12, article 656621, 2021.

[20] H. Chen, Study on the Protective Mechanism of Apelin Peptide on Pancreatic and Renal Injury, [Ph.D Thesis], Huazhong University of Science and Technology, Hubei, 2014.

[21] The microvascular complications Group of Diabetes Association of the Chinese Medical Association, "The expert consensus of diabetic kidney disease prevention and control," Chin Journal Diabetes Mellitus, vol. 6, no. 11, pp. 792-801, 2014.

[22] G. D. Sun, C. Y. Li, W. P. Cui et al., "Review of herbal traditional chinese medicine for the treatment of diabetic nephropathy," Journal Diabetes Research, vol. 2016, article 5749857, 18 pages, 2016.

[23] G. Schernthaner and G. H. Schernthaner, "Diabetic nephropathy: new approaches for improving glycemic control and reducing risk," Journal of Nephrology, vol. 26, no. 6, pp. 975985, 2013.

[24] H. Skali, A. Shah, D. K. Gupta et al., "Cardiac structure and function across the glycemic spectrum in elderly men and women free of prevalent heart disease: the Atherosclerosis Risk
In the Community study," Circulation. Heart Failure, vol. 8, no. 3, pp. 448-454, 2015.

[25] S. Hwang, J. Park, J. Kim et al., “Tissue expression of tubular injury markers is associated with renal function decline in diabetic nephropathy," Journal of Diabetes and its Complications, vol. 31, no. 12, pp. 1704-1709, 2017.

[26] A. Porzionato, V. Macchi, M. Rucinski, L. K. Malendowicz, and R. De Caro, "Natriuretic peptides in the regulation of the hypothalamic-pituitary-adrenal axis," International Review of Cell and Molecular Biology, vol. 280, pp. 1-39, 2010.

[27] P. J. Saulnier, E. Gand, G. Velho et al., "Association of circulating biomarkers (adrenomedullin, TNFR1, and NT-proBNP) with renal function decline in patients with type 2 Diabetes: A french prospective cohort," Diabetes Care, vol. 40, no. 3, pp. 367-374, 2017.

[28] L. Yuan, "The significance of combined detection of brain natriuretic peptide, cystatin $\mathrm{c}$ and homocysteine in the diagnosis of early diabetic nephropathy," Zhejiang Practical Medicine, vol. 18, no. 4, pp. 240-241, 2013.

[29] X. Wang and D. Zheng, "The significance of detecting type B brain natriuretic peptide in patients with diabetic nephropathy," Chinese Journal of Gerontology, vol. 33, no. 14, pp. 3450-3451, 2013.

[30] H. Dai, L. Chen, D. Gao, and A. Fei, "Phosphocreatine attenuates isoproterenol-induced cardiac fibrosis and cardiomyocyte apoptosis," BioMed Research International, vol. 2019, Article ID 5408289, 7 pages, 2019.

[31] M. Dou, L. Di, L. L. Zhou et al., "Cochlearols A and B, polycyclic meroterpenoids from the fungus Ganoderma cochlear that have renoprotective activities," Organic Letters, vol. 16, pp. 6064-6067, 2014.

[32] S. Horita, M. Nakamura, M. Suzuki, N. Satoh, A. Suzuki, and G. Seki, "Selective insulin resistance in the kidney," BioMed Research International, vol. 2016, Article ID 5825170, 8 pages, 2016.

[33] Q. Lu, W. Z. Zuo, X. J. Ji et al., "Ethanolic Ginkgo biloba leaf extract prevents renal fibrosis through Akt/mTOR signaling in diabetic nephropathy," Phytomedicine, vol. 22, no. 12, pp. 1071-1078, 2015.

[34] Y. Li, Z. Zhao, and W. Liu, "Regulation of autophagy by PI3K/ Akt / mTOR signaling pathway in hormonal ischemic necrosis of the femoral head," China Tissue Engineering Research, vol. 23, no. 12, pp. 1921-1929, 2019.

[35] H. Yang and S. Wu, "Retracted Article: Ligustrazine attenuates renal damage by inhibiting endoplasmic reticulum stress in diabetic nephropathy by inactivating MAPK pathways," RSC advances, vol. 8, no. 39, pp. 21816-21822, 2018.

[36] L. Espert, M. Denizot, M. Grimaldi et al., “Autophagy is involved in T cell death after binding of HIV-1 envelope proteins to CXCR4," The Journal of Clinical Investigation, vol. 116, no. 8, pp. 2161-2172, 2006.

[37] S. Bernales, K. I. McDonald, and P. Walter, "Autophagy counterbalances endoplasmic reticulum expansion during the unfolded protein response," PLoS Biology, vol. 4, no. 12, article e423, 2006.

[38] J. Puyal, V. Ginet, Y. Grishchuk, A. C. Truttmann, and P. G. H. Clarke, "Neuronal autophagy as a mediator of life and Death," The Neuroscientist, vol. 18, no. 3, pp. 224-236, 2012.

[39] K. Chen, X. Lv, W. Li et al., "Autophagy is a protective response to the oxidative damage to endplate chondrocytes in intervertebral disc: implications for the treatment of 
degenerative lumbar disc," Oxidative Medicine and Cellular Longevity, vol. 2017, Article ID 4041768, 9 pages, 2017.

[40] M. C. Maiuri, G. le Toumelin, A. Criollo et al., "Functional and physical interaction between Bcl-XL and a BH3-like domain in Beclin-1," The EMBO Journal, vol. 26, no. 10, pp. 2527-2539, 2007.

[41] V. Deretic, T. Saitoh, and S. Akira, "Autophagy in infection, inflammation and immunity," Nature Reviews. Immunology, vol. 13, no. 10, pp. 722-737, 2013.

[42] J. F. Navarro-González, C. Mora-Fernández, M. M. de Fuentes, and J. García-Pérez, "Inflammatory molecules and pathways in the pathogenesis of diabetic nephropathy," Nature Reviews. Nephrology, vol. 7, no. 6, pp. 327-340, 2011.

[43] T. Saitoh, N. Fujita, M. H. Jang et al., "Loss of the autophagy protein Atg16L1 enhances endotoxin-induced IL-1 $\beta$ production," Nature, vol. 456, no. 7219, p. 264, 2008.

[44] D. S. Arroyo, E. A. Gaviglio, J. M. Ramos, C. Bussi, M. C. Rodriguez-Galan, and P. Iribarren, "Autophagy in inflammation, infection, neurodegeneration and cancer," International Immunopharmacology, vol. 18, no. 1, pp. 55-65, 2014.

[45] T. Kimura, Y. Isaka, and T. Yoshimori, "Autophagy and kidney inflammation," Autophagy, vol. 13, no. 6, pp. 997-1003, 2017.

[46] J. Ma, H. Rui, Q. Chen, Z. H. Wang, and Y. Cheng, “Antiinflammatory activity and therapeutic effect of Ganoderma lucidum polysaccharide on streptozotocin-induced diabetic nephropathy in mice," Journal of Nanjing Medical University (Natural Science Edition), vol. 39, no. 3, pp. 326-331, 2019.

[47] Y. Aso, N. Yoshida, K. Okumura et al., "Coagulation and inflammation in overt diabetic nephropathy: association with hyperhomocysteinemia," Clinica Chimica Acta, vol. 348, no. 1-2, pp. 139-145, 2004.

[48] D. U. Nguyen, F. U. Ping, W. E. Mu, P. Hill, R. C. Atkins, and S. J. Chadban, "Macrophage accumulation in human progressive diabetic nephropathy," Nephrology (Carlton, Vic), vol. 11, no. 3, pp. 226-231, 2006.

[49] F. Barutta, G. Bruno, S. Grimaldi, and G. Gruden, "Inflammation in diabetic nephropathy: moving toward clinical biomarkers and targets for treatment," Endocrine, vol. 48, no. 3, pp. 730-742, 2015.

[50] P. Geng, D. Zhong, L. Su, Z. Lin, and B. Yang, "Preventive and therapeutic effect of Ganoderma lucidum on kidney injuries and diseases," Advances in Pharmacology, vol. 87, pp. 257276, 2020.

[51] D. Pan, D. Zhang, J. Wu et al., "A novel proteoglycan from Ganoderma lucidum fruiting bodies protects kidney function and ameliorates diabetic nephropathy via its antioxidant activity in C57BL/6 db/db mice," Food and Chemical Toxicology, vol. 63, no. 111-118, pp. 111-118, 2014.

[52] F. Shaher, S. Wang, H. Qiu et al., "Effect and mechanism of Ganoderma lucidum spores on alleviation of diabetic cardiomyopathy in a pilot in vivo Study," Diabetes, Metabolic Syndrome and Obesity: Targets and Therapy, vol. Volume 13, pp. 4809-4822, 2020.

[53] F. Shaher, H. Qiu, S. Wang et al., "Associated targets of the antioxidant cardioprotection of Ganoderma lucidum in diabetic cardiomyopathy by using open targets platform: a systematic review," BioMed Research International, vol. 2020, Article ID 7136075, 20 pages, 2020.

[54] H. N. Li, L. L. Zhao, and D. Q. Di Yi Zhou, "Ganoderma lucidum polysaccharides ameliorates hepatic steatosis and oxida- tive stress in $\mathrm{db} / \mathrm{db}$ mice via targeting nuclear factor $\mathrm{E} 2$ (erythroid-derived 2)-related factor-2/heme oxygenase-1 (HO-1) pathway," Medical Science Monitor: international medical journal of experimental and clinical research, vol. 26, article e921905, 2020.

[55] H. Liang, Y. Pan, Y. Teng et al., "A proteoglycan extract fromGanoderma Lucidumprotects pancreatic beta-cells against STZ-induced apoptosis," Bioscience, Biotechnology, and Biochemistry, vol. 84, no. 12, pp. 2491-2498, 2020.

[56] K.-J. Wu, S.-Q. Wang, R.-P. Shi et al., "Neuroprotective effect of Ganoderma lucidum polysaccharides on epilepsy in a rat's epileptic model," Current Topics in Nutraceutical Research, vol. 20 , no. $2,2022$.

[57] Z. M. Jiang, H. B. Qiu, S. Q. Wang, J. Guo, Z. W. Yang, and S. Zhou, "Ganoderic acid A potentiates the antioxidant effect and protection of mitochondrial membranes and reduces the apoptosis rate in primary hippocampal neurons in magnesium free medium," Die Pharmazie-An International Journal of Pharmaceutical Sciences, vol. 73, no. 2, pp. 87-91, 2018.

[58] S. Zhou, S. Q. Wang, C. Y. Sun et al., "Investigation into antiepileptic effect and mechanisms of Ganoderma lucidum polysaccharides inin vivoandin vitromodels," Proceedings of the Nutritional Society, vol. 74, no. OCE1, p. E65, 2015.

[59] S. Q. Wang, X. J. Li, H. B. Qiu et al., "Anti-epileptic effect of Ganoderma lucidum polysaccharides by inhibition of intracellular calcium accumulation and stimulation of expression of CaMKII $\alpha$ in epileptic hippocampal neurons," PLoS ONE, vol. 9, no. 7, article e102161, 2014.

[60] S. Q. Wang, X. J. Li, S. Zhou et al., "Intervention effects of Ganoderma lucidum spores on epileptiform discharge hippocampal neurons and expression of neurotrophin- 4 and N-cadherin," PLoS One, vol. 8, no. 4, article e61687, 2013. 